\title{
Influence of Dip Angle on Non-Anti-Symmetry Response of Tunnels in Bedding Rock Mass Due to Seismic qSV Wave Propagation
}

\author{
$\mathrm{HY} \mathrm{Hu}^{1,2}, \mathrm{XJ} \mathrm{Zhou}^{1,2}$, and T Chen ${ }^{3,4}$ \\ ${ }^{1}$ Key Laboratory of Transportation Tunnel Engineering, Ministry of Education,Southwest Jiaotong University, Chengdu, Sichuan 610031, \\ China; \\ ${ }^{2}$ School of Civil Engineering, Southwest Jiaotong University, Chengdu, Sichuan 610031, China; \\ ${ }^{3}$ School of Transportation and Logistics, Southwest Jiaotong University, Chengdu,610031, China; \\ ${ }^{4}$ National Railway Train Diagram Research and Training Center, Southwest JiaoTong University, Chengdu,610031, China.
}

\begin{abstract}
By considering the transverse isotropic constitutive law of the bedding rock mass and using the wave method to analyze a high-speed railway tunnel in a bedding rock mass, we studied the influence of dip angle on nonanti-symmetry response of tunnels in bedding rock mass due to seismic qsv wave propagation. The results show that the non-anti-symmetry of tunnel seismic response does not obey linear relationship with the change of rock dip, and the variation law is segmental; the moment of seismic response is anti-symmetric strictly when the rock layer is vertical or horizontal, and it is non-anti-symmetrical when the rock layer is inclined; within each segmented interval, the non-anti-symmetry of seismic response increases first and then decreases with the increase of dip angle. This indicates that the influence of dip angle on the non-anti-symmetry of tunnel seismic response is significant.
\end{abstract}

\section{Introduction}

Under the action of seismic qSV wave (i.e. quasi-SV wave ), the seismic response of homogeneous rock tunnel is anti-symmetric, but the seismic response of bedding rock tunnel (i.e. the strike line of strata is parallel to the tunnel axis, the dip direction is perpendicular to the tunnel axis ) is non-anti-symmetric. The non-anti-symmetric is due to the transverse isotropic constitutive law of bedding rock mass[1]. However, in recent years, scholars' research focused more on homogeneous rock tunnels[2-7], in other words, the current studies considered bedding rock mass as an isotropic medium, this does not reflect the non-antisymmetry of the seismic response, and the influence of dip angle on the non-anti-symmetry[8-14].

So, the transverse isotropic constitutive law of bedding rock mass was considered, and a high-speed railway tunnel in a bedding rock mass was took as an engineering background, and then the numerical analysis of seismic response was carried out by using ANSYS to study the influence of dip angle on non-anti-symmetry of tunnel seismic response caused by incident qSV wave.

\section{Material parameters and calculation model}

\subsection{Lining parameters}

A typical excavation section of high-speed railway deep tunnel is shown as Figure 1, the maximum width of tunnel excavation section is $15 \mathrm{~m}$. The parameters of tunnel secondary lining are: thickness is $600 \mathrm{~mm}, \mathrm{C} 35$ concrete, reinforcement ratio is $0.35 \%$, modulus of elasticity is $31.5 \mathrm{GPa}$, Poisson's ratio is 0.2 , Bulk weight is $25 \mathrm{kN} / \mathrm{m}^{3}$. In order to observe the characteristics of seismic response of tunnel in bedding rock mass more clearly, the reinforcement layer and initial support are omitted in study.

\subsection{Bedding rock mass parameters}

Without loss of generality, the dip angles of $0^{\circ}, 25^{\circ}, 45^{\circ}$, $70^{\circ}$ and $90^{\circ}$ of the rock mass and two groups of bedding rock mass parameters D1 and D2 are selected, see Table 1 for details; And five dip angles of $0^{\circ}, 25^{\circ}, 45^{\circ}, 70^{\circ}$ and $90^{\circ}$ are selected. Therefore, there are 10 combinations of work conditions, as is shown in Table 2.

\subsection{Calculation model}

The plane strain finite element model of a tunnel in a bedding rock mass takes the tunnel as the centre and intercepts a square area of $1000 \mathrm{~m} \times 1000 \mathrm{~m}$ in the infinite rock mass domain. And ANSYS software was used for seismic response analysis, where the rock mass is simulated by element plane 42 , the lining is simulated by element beam 3 and the viscoelastic boundary is simulated by element combin 14 , and the integral step is $0.01 \mathrm{~s}$. The calculation of the viscoelastic boundary spring-damping parameters is detailed in [1], where the normal correction factor $\alpha_{\mathrm{N}}$ and the tangential correction factor $\alpha_{\mathrm{T}}$ are taken as 1.0 and 0.5 respectively [15]. 
Table 1. Bedding rock mass parameters

\begin{tabular}{ccccccc}
\hline & \multicolumn{5}{c}{ Elastic constants } \\
\cline { 3 - 7 } $\begin{array}{c}\text { Rock mass } \\
\text { group }\end{array}$ & $\begin{array}{c}\text { Density } \\
\left(\mathrm{kg} \cdot \mathrm{m}^{-3}\right)\end{array}$ & $\begin{array}{c}\text { In-Plane Elastic } \\
\text { Modulus } \\
(\mathrm{GPa})\end{array}$ & $\begin{array}{c}\text { Symmetrical } \\
\text { Axial Elastic } \\
\text { Modulus } \\
(\mathrm{GPa})\end{array}$ & $\begin{array}{c}\text { In-Plane } \\
\text { Poisson Ratio }\end{array}$ & $\begin{array}{c}\text { Symmetrical } \\
\text { Axial Poisson } \\
\text { Ratio }\end{array}$ & $\begin{array}{c}\text { Symmetrical } \\
\text { Axial Shear } \\
\text { Modulus } \\
(\mathrm{GPa})\end{array}$ \\
\hline D1 & 2700 & 22.0 & 17.0 & 0.24 & 0.26 & 7.2 \\
D2 & 2700 & 22.0 & 13.0 & 0.24 & 0.26 & 5.2 \\
\hline
\end{tabular}

In order to reveal the general response characteristics of tunnels in bedding rock mass, the total wave field of the seismic wave only contains the incident wave field and the tunnel reflection wave field, and four viscoelastic boundaries of the finite calculation area were set. And the tunnel reflection wave is naturally absorbed by the viscoelastic boundaries.

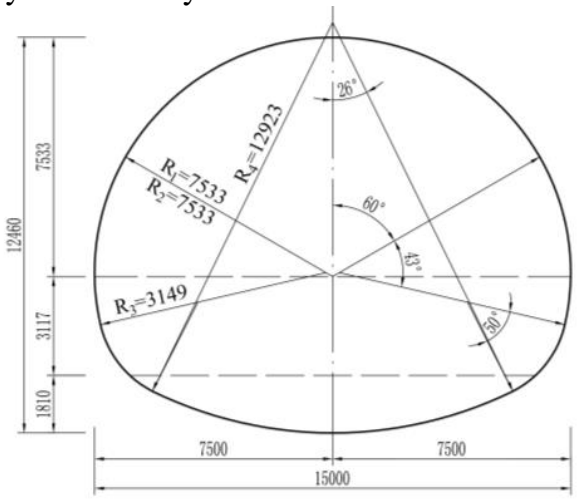

Figure 1 Tunnel excavation section (Unit: $\mathrm{mm}$ )

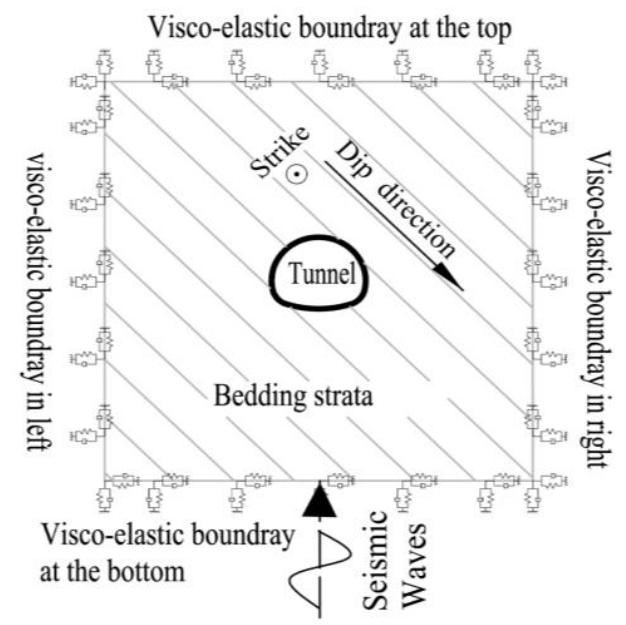

Figure 2. Schematic of calculation model

The incident wave may be located in any direction of the tunnel in actual, however, when the direction of incident seismic wave is on the symmetry axis of the tunnel section, the lining response of non-antisymmetry caused by rock anisotropy can be presented effectively, for that the transverse component of the $\mathrm{qSV}$ is perpendicular to the symmetry axis of the tunnel section and the lining on the axis symmetry. And based on the non-symmetry of the response, the influence of dip angle on the seismic response of the tunnel can be studied. Therefore, the direction of the incident seismic wave was set on the symmetry axis of the tunnel section. 2.

The resulting calculation model is shown as Figure

\section{Incident qSV Wave}

The Wolong wave in Wenchuan earthquake was selected, and the most violent of the 10 21s band was extracted, filtered and baseline corrected, and the resulting displacement time and velocity time history are shown in Figure 3 and Figure 4.

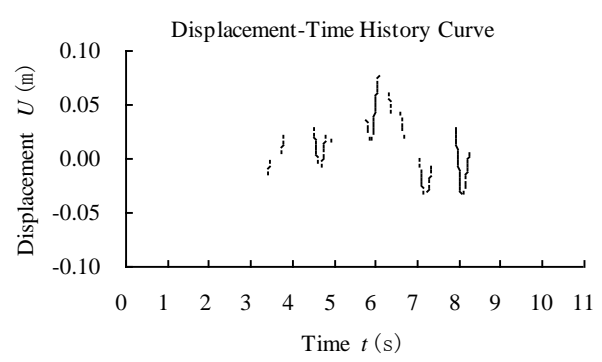

Figure 3. Displacement-Time History Curve of Incident Wave

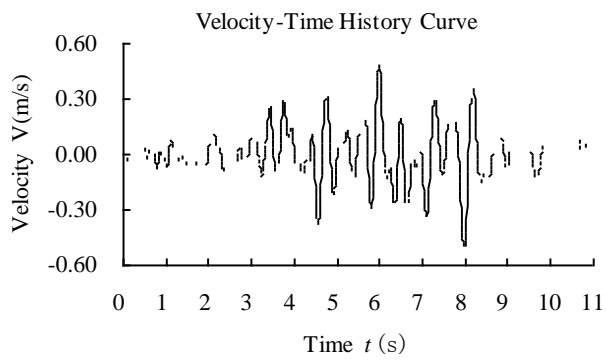

Figure 4. Velocity-Time History Curve of Incident Wave

\section{Results and Analysis of Moment Envelope}

Moment envelope is a very representative seismic response. The envelope of the tunnel lining moment in each work condition are shown respectively in Figure 5 for D1 rock mass group and Figure 6 for D3 rock mass group, and the moment of the arch foot is shown in Table 2. According to Figure 5 and Figure 6: the envelope of bending moments in D1 and D3 rock mass groups are very similar, and the extreme value of moments are all located at the arch foot, but the values are different. Further, according to Table 2: when the rock stratum is horizontal or vertical, the moment envelope is left-right anti-symmetric; and when the rock stratum is inclined, the moment envelope is non-antisymmetric. 


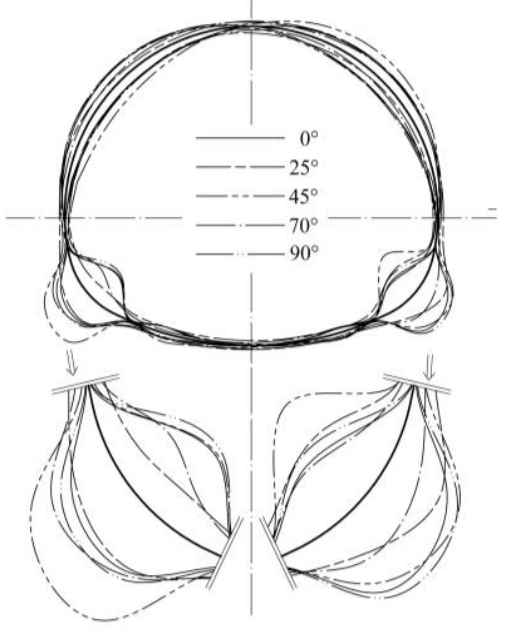

Figure 5. Moment Envelope of tunnel lining in D1 Rock Mass Group

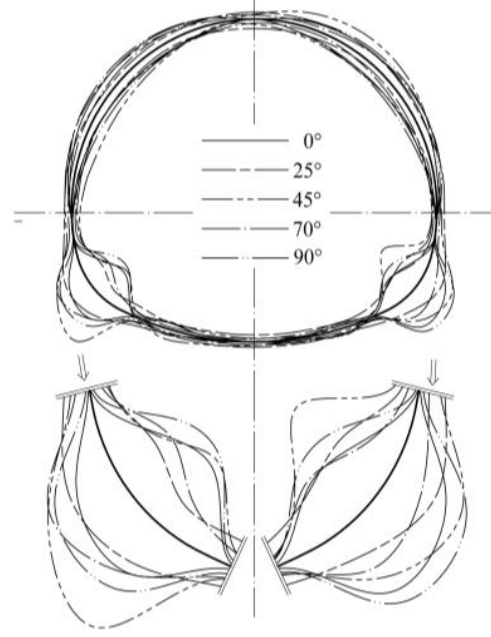

Figure 6. Moment Envelope of tunnel lining in D2 Rock Mass Group

Table 2. Peak Moment Comparison Table for qSV Waves

\begin{tabular}{|c|c|c|c|c|c|c|c|c|c|}
\hline \multirow{2}{*}{$\begin{array}{l}\text { Cond- } \\
\text { ition }^{\mathrm{a}}\end{array}$} & \multicolumn{2}{|c|}{ Left Foot } & \multicolumn{2}{|c|}{ Right Foot } & \multirow{2}{*}{$\begin{array}{l}\text { Cond- } \\
\text { ition }^{\mathrm{a}}\end{array}$} & \multicolumn{2}{|c|}{ Left Foot } & \multicolumn{2}{|c|}{ Right Foot } \\
\hline & $\begin{array}{l}\text { Moment } \\
\text { (kN.m) }\end{array}$ & $\begin{array}{l}\text { Time } \\
\text { (s) }\end{array}$ & $\begin{array}{l}\text { Moment } \\
\text { (kN.m) }\end{array}$ & $\begin{array}{l}\text { Time } \\
\text { (s) }\end{array}$ & & $\begin{array}{l}\text { Moment } \\
\text { (kN.m) }\end{array}$ & $\begin{array}{l}\text { Time } \\
\text { (s) }\end{array}$ & $\begin{array}{l}\text { Moment } \\
\text { (kN.m) }\end{array}$ & $\begin{array}{l}\text { Time } \\
\text { (s) }\end{array}$ \\
\hline \multirow{2}{*}{ D1-0 $0^{\circ}$} & 1420.09 & 6.71 & -1420.44 & 6.71 & \multirow{2}{*}{$\mathrm{D} 2-0^{\circ}$} & 1388.80 & 6.18 & -1389.91 & 6.18 \\
\hline & -1961.00 & 8.21 & 1961.48 & 8.21 & & -1938.47 & 8.20 & 1937.30 & 8.20 \\
\hline \multirow{2}{*}{ D1-25 } & 1352.31 & 8.31 & -1709.51 & 8.31 & \multirow{2}{*}{$\mathrm{D} 2-25^{\circ}$} & 1345.22 & 8.19 & -1524.94 & 8.34 \\
\hline & -854.32 & 5.97 & 1480.02 & 5.98 & & -1203.42 & 5.85 & 1269.87 & 6.00 \\
\hline \multirow{2}{*}{ D1-45 ${ }^{\circ}$} & 2801.40 & 8.35 & -2795.12 & 8.35 & \multirow{2}{*}{$\mathrm{D} 2-45^{\circ}$} & 2992.65 & 8.36 & -2907.72 & 8.36 \\
\hline & -2017.87 & 6.85 & 2024.10 & 6.85 & & -2136.09 & 6.86 & 2034.92 & 6.86 \\
\hline \multirow{2}{*}{$\mathrm{D} 1-70^{\circ}$} & 1773.55 & 8.27 & -1365.46 & 8.27 & \multirow{2}{*}{$\mathrm{D} 2-70^{\circ}$} & 1975.84 & 8.27 & -1484.78 & 8.27 \\
\hline & -1472.44 & 6.77 & 1088.13 & 6.77 & & -1620.57 & 6.77 & 1214.69 & 6.77 \\
\hline \multirow{2}{*}{$\mathrm{D} 1-90^{\circ}$} & 1632.05 & 6.71 & -1631.93 & 6.71 & \multirow{2}{*}{$\mathrm{D} 2-90^{\circ}$} & 1865.78 & 6.70 & -1864.01 & 6.70 \\
\hline & -2131.78 & 8.21 & 2132.02 & 8.21 & & -2268.35 & 8.20 & 2266.84 & 8.20 \\
\hline
\end{tabular}

a Work condition number agreement as follows: Take D1- $0^{\circ}$ as an example, D1 is the rock mass group, $0^{\circ}$ is the dip angle, and the rest is analogy.

To analyze the relationship between the non-antisymmetry and dip angle, the parameter Moment Sum of Left and Right Foot $\chi^{\mathrm{M}}$ is defined as:

$\chi^{\mathrm{M}}=$ Moment of Left Foot + Moment of Right Foot

The maximum and minimum values of arch moment envelope are substituted into equation (1) to calculate the sum of bending moments and draw Figure 7. According to Figure 7, the relationship between the non-antisymmetry of the bending moment envelope and the dip angle is non-linear: when the dip angle $\theta^{0}$ is about $45^{\circ}$, the absolute value of the bending moment on the left and right arches is almost equal, and when $\theta^{\circ}$ is $0^{\circ}$ or $90^{\circ}$, the absolute value of the bending moment on the left and right arches is strictly equal, i.e. the moment of seismic response is anti-symmetric strictly. Overall, the absolute value of left arch moment is larger than that of right arch when $\theta^{0} \in\left(0^{\circ}, 45^{\circ}\right)$, and the non-anti-symmetry increases first, then decreases with the increase of dip angle, and the highest at about $25^{\circ}$; the absolute value of left arch moment is smaller than that of the right arch when $\theta^{\circ} \in\left(45^{\circ}, 90^{\circ}\right)$, and the non-anti-symmetry first increases and then decreases with the increase of dip angle, and the highest at about $75^{\circ}$.

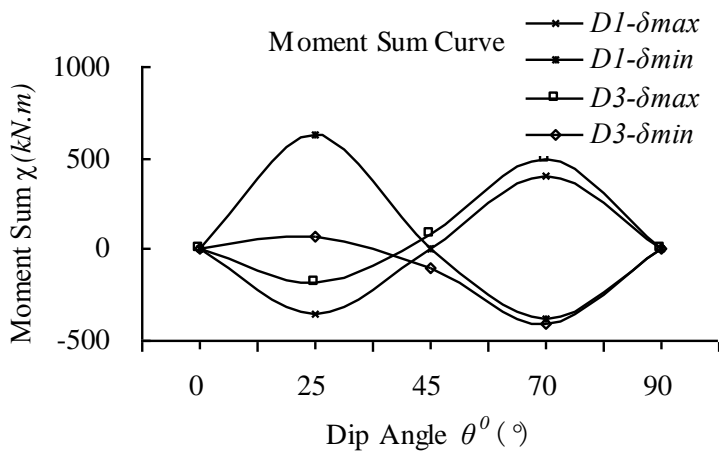

Figure 7. Moment Sum of Left and right foot (Envelope)

\section{Results and Analysis of Relative Displacement}

The layout of tunnel lining section displacement detection points $\mathrm{A} \sim \mathrm{H}$ is shown in Figure 8. The relative displacement between the detection points in the section is shown in Table 3. In table 3: $\mathrm{d}_{\mathrm{BG}}$ is the relative displacement between the detection points $\mathrm{B}$ and $\mathrm{G}$ at the same time, other analogies; And the relative distance between the points is a positive number when it is larger than the original distance, on the contrary, it is negative. 
Table 3. Relative Displacements (unit: $\mathrm{mm}$ )

\begin{tabular}{cccccccc}
\hline \multirow{2}{*}{$\begin{array}{c}\text { Cond- } \\
\text { ition }\end{array}$} & \multirow{2}{*}{ Time/s } & \multicolumn{3}{c}{ Diagonal relative displacement } & \multicolumn{3}{c}{ Horizontal relative displacement } \\
\cline { 3 - 8 } & & $\mathrm{d}_{\mathrm{BG}}$ & $\mathrm{d}_{\mathrm{CF}}$ & $\mathrm{d}_{\mathrm{AH}}$ & $\mathrm{d}_{\mathrm{BC}}$ & $\mathrm{d}_{\mathrm{DE}}$ & $\mathrm{d}_{\mathrm{FG}}$ \\
\hline \multirow{2}{*}{$\mathrm{D} 1-0^{\circ}$} & 6.71 & 46.67 & -46.66 & 0.12 & 0.04 & 0.04 & 0.03 \\
& 8.21 & -63.98 & 63.98 & 0.21 & 0.07 & 0.07 & 0.06 \\
\hline \multirow{2}{*}{$\mathrm{D} 1-25^{\circ}$} & 8.31 & 38.60 & -62.94 & -19.12 & -6.58 & -7.70 & -4.90 \\
& 5.97 & -16.60 & 33.36 & 41.03 & -8.03 & -13.50 & -9.48 \\
\hline \multirow{2}{*}{$\mathrm{D} 1-45^{\circ}$} & 8.35 & 90.00 & -91.66 & -14.87 & 6.79 & 10.63 & 6.26 \\
& 6.85 & -64.92 & 66.33 & 12.14 & -5.09 & -7.92 & -4.63 \\
\hline \multirow{2}{*}{$\mathrm{D} 1-70^{\circ}$} & 8.27 & 54.92 & -42.62 & 17.70 & 0.17 & -0.79 & -1.44 \\
& 6.77 & -37.33 & 31.70 & -23.34 & 6.82 & 10.91 & 8.14 \\
\hline \multirow{2}{*}{$\mathrm{D} 1-90^{\circ}$} & 6.71 & 54.52 & -54.52 & 0.17 & 0.04 & 0.04 & 0.04 \\
& 8.21 & -11.83 & 11.84 & 0.02 & 0.01 & 0.01 & 0.01 \\
\hline \multirow{2}{*}{$\mathrm{D} 2-0^{\circ}$} & 6.18 & 45.25 & -45.25 & 0.08 & 0.06 & 0.01 & 0.05 \\
& 8.2 & -62.09 & 62.09 & 0.17 & 0.08 & 0.01 & 0.07 \\
\hline \multirow{2}{*}{$\mathrm{D} 2-25^{\circ}$} & 8.19 & 10.71 & 9.29 & 64.19 & -16.45 & -25.87 & -17.67 \\
& 5.85 & -18.68 & 14.34 & -33.58 & 12.14 & 18.50 & 12.78 \\
\hline \multirow{2}{*}{$\mathrm{D} 2-45^{\circ}$} & 8.36 & 85.99 & -89.06 & -32.99 & 14.85 & 23.36 & 13.77 \\
& 6.86 & -61.71 & 63.55 & 22.35 & -10.10 & -15.71 & -9.07 \\
\hline \multirow{2}{*}{$\mathrm{D} 2-70^{\circ}$} & 8.27 & 50.95 & -47.97 & 23.10 & -7.91 & -12.38 & -9.65 \\
& 6.77 & -39.06 & 39.13 & -20.88 & 9.01 & 13.95 & 10.52 \\
\hline \multirow{2}{*}{$\mathrm{D} 2-90^{\circ}$} & 6.7 & 62.37 & -62.36 & 0.21 & 0.06 & 0.06 & 0.05 \\
& 8.2 & -75.65 & 75.65 & 0.30 & 0.09 & 0.09 & 0.08 \\
\hline \multirow{2}{*}{2} & & & & & & &
\end{tabular}

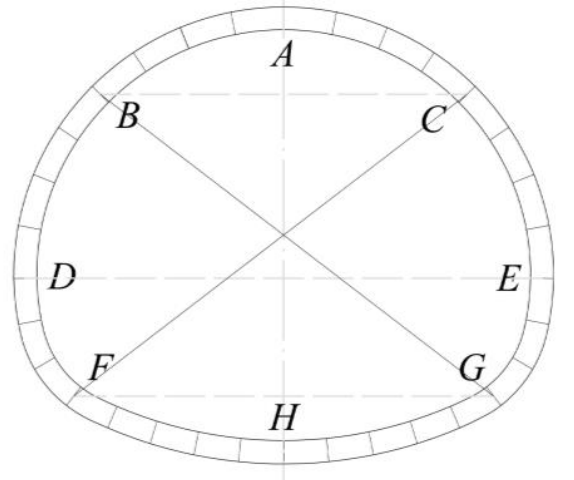

Figure 8. Lining Unit Number and Detection Points

According to table 3: when the rock stratum is horizontal or vertical, the relative displacements is leftright anti-symmetric; and when the rock stratum is inclined, the relative displacements is non-anti-symmetric.

To analyze the relationship between the non-antisymmetry and dip angle, the parameter Diagonal Displacements Sum of Left and Right $U^{\mathrm{M}}$, is defined as:

$$
U^{\mathrm{M}}=\mathrm{d}_{\mathrm{BG}}+\mathrm{d}_{\mathrm{CF}}
$$

The relative displacements are substituted into equation (2) to calculate the sum of diagonal displacements and draw Figure 9. According to Figure 9, the relationship between the non-anti-symmetry of the bending moment envelope and the dip angle is non-linear: when the dip angle $\theta^{0}$ is about $45^{\circ}$, the absolute value of the diagonal relative displacements on the left and right is almost equal, and when $\theta^{\circ}$ is $0^{\circ}$ or $90^{\circ}$, the absolute value of the diagonal relative displacements on the left and right is strictly equal, i.e. the diagonal relative displacements of seismic response is anti-symmetric strictly. Overall, the absolute value of left arch diagonal relative displacements is larger than that of right when $\theta^{\circ} \in\left(0^{\circ}, 45^{\circ}\right)$, and the nonanti-symmetry increases first, then decreases with the increase of dip angle, and the highest at about $25^{\circ}$; the absolute value of left relative displacement is smaller than that of the right when $\theta^{0} \in\left(45^{\circ}, 90^{\circ}\right)$, and the non-antisymmetry first increases and then decreases with the increase of dip angle, and the highest at about $70^{\circ}$.

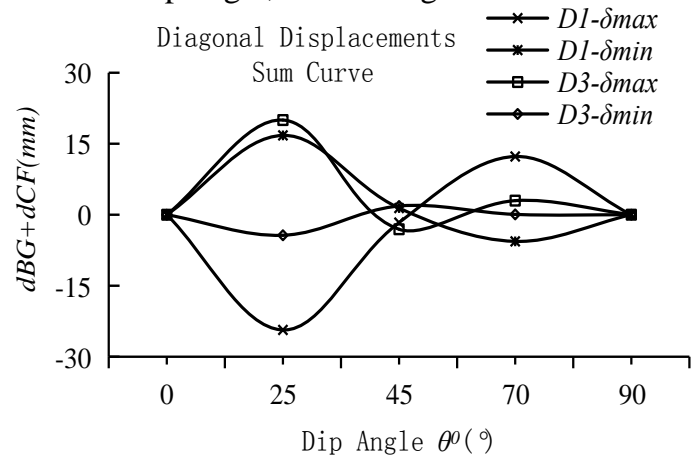

FiFigure 9. Diagonal Displacements Sum

(Meanwhile)

\section{Conclusion}

The influence of dip angle on non-anti-symmetry response of tunnels in bedding rock mass is due to seismic qSV wave propagation:

(1) The non-anti-symmetry of the seismic response obeys the non-linear relationship with the dip, and with segmentation. And the moment of seismic response is anti-symmetric strictly when the rock layer is vertical or horizontal, and it is non-anti-symmetrical when the rock layer is inclined.

(2) In all work conditions of this paper, when the dip angle $\theta^{0}$ is about $45^{\circ}$, the non-anti-symmetry behaves as a non-strict anti-symmetry, and when $\theta^{\circ} \in\left(0^{\circ}, 45^{\circ}\right)$, the non-anti-symmetry first increases and then decreases with the increase of dip angle, and the strongest non-antisymmetry is at about $25^{\circ}$; when $\theta^{0} \in\left(45^{\circ}, 90^{\circ}\right)$, the nonanti-symmetry first increases and then decreases with the 
increase of dip angle, and the strongest non-antisymmetry is at about $70^{\circ}$ or $75^{\circ}$.

(3) The influence of dip angle on the non-antisymmetry of tunnel seismic response is significant and requires further study.

\section{Acknowledgement}

The authors appreciate the support from the National Natural Science Foundation of China (Project No. 51378436, 61703351), and the Fundamental Research Funds for the Central Universities(No. 2682017CX022).

\section{Reference}

1. Hu H, Zhou X and Wang J 2017. CJRME. 36 137383

2. Hashash Y, Hook J, Schmidt B and Yao J 2001. TUNN. UNDERGR. SP. TECH. 16 247-93.

3. Esmaeili M, Vahdani S and Noorzad A 2006. TUNN. UNDERGR. SP. TECH. 21 511-9.

4. Park K, Tantayopin K, Tontavanich B and Owatsiriwong A 2009. TUNN. UNDERGR. SP. TECH. 24 231-5.
5. Cilingir $\mathrm{U}$ and Madabhushi S 2011. SOIL DYN. EARTHQ. ENG. 31 452-62.

6. Kouretzis G, Sloan S and Carter J 2013. SOIL DYN. EARTHQ. ENG. 46 41-51

7. He C, Li L, Zhang J, Geng P and Yan Q 2014. Chinese Journal of Geotechnical Engineering. 36 427-34. in Chinese

8. Han S, Zhang W and Zhang J 2017. Geophys. J. Int. $2101560-1569$

9. Cheng J and Kang W 2016. GEOPHYSICS. 81 C39C52

10. Brijendra Paswan B, Sahu S and Chattopadhyay A 2016. Acta Mech. 227 3687-3701

11. Sharma J and Kaur R 2014. LAT AM J SOLIDS STRU. 11 2141-2170

12. Ba Z, Lee V, Liang $\mathrm{J}$ and Yan Y 2017. SOIL DYN EARTHQ ENG. 98 120-140

13. Ba $\mathrm{Z}$ and Liang $\mathrm{J}$ 2017. ENG ANAL BOUND ELEM. 76 40-58

14. Modi C, Kumari $\mathrm{P}$ and Sharma V 2016. APPL MATH MODEL. 40 8737-8749

15. Liu J, Du Y and Yan Q 2007. Journal of Disaster Prevention and Mitigation Engineering 27(Supplement) 37-42. in Chinese 